\title{
La rehabilitación ontológica de la imagen: Heidegger lector de Kant
}

\section{The ontological rehabilitation of image: \\ Heidegger reader of Kant}

Prof. Dr. Roberto Rubio

rorubio@uahurtado.cl

Universidad Alberto Hurtado, Chile

Entre los intérpretes de Heidegger predomina una lectura que destaca la postura negativa de Heidegger hacia la producción, la exhibición (Darstellung) y la imagen. En dicha lectura ocupan el centro de la atención la crítica heideggeriana al modelo de la producción, efectuada a lo largo de los años Veinte, así como su enfática crítica a la exhibición en la conferencia sobre el origen de la obra de arte, y muy especialmente la noción de imagen presentada en la conferencia "La época de la imagen del mundo".

Sin embargo, esto es solo un aspecto de la elaboración heideggeriana sobre el fenómeno de la imagen. Se trata, por así decir, de la pars destruens de un proyecto mayor. Los intérpretes suelen pasar por alto precisamente la pars construens, esto es, el momento propositivo. En el presente trabajo quisiera mostrar, en primer lugar, que la crítica heideggeriana a la producción y a la imagen es al reverso una tarea positiva de apropiación, esto es, la elaboración de una ontología de la imagen o figura de cuño propio. En segundo lugar, mostraré cómo Heidegger llevó a cabo dicha ontología de la imagen mediante una creativa recepción de Kant, focalizada en la cuestión de la exhibitio originaria.

PALABRAS CLAVE imagen, ontología, exhibitio originaria, Heidegger, Kant 
Among Heidegger's interpreters predominate a reading that highlights the negative stance of Heidegger for the production, the exhibition (Darstellung) and the image. In this reading the center of attention is occupied by the Heideggerian critique to the production model made during the twenties, as well as his emphatic critique to exhibition in conference on the origin of the work of art, and specially the notion of image or picture presented in conference "The age of world picture".

However, this is just one aspect of the heideggerian elaboration on the phenomenon of image. So to speak, it is the pars destruens of a larger project. The interpreters overlooked precisely the pars construens, that is, the propositional moment. In this at work I want to show, in first place, that the Heideggerian critique to the production and image is in reverse a positive task of appropriation, that is, the development of his own ontology of the image or figure.

Secondly, I will show how Heidegger carried out his ontology of image by a creative reception of Kant, focused in the question of the exhibition originaria.

KEYWORDS image, ontology, exhibitio originaria, Heidegger, Kant 
La peculiaridad ontológica de la imagen o figura (Bild) es un tema de interés constante en la filosofía de Heidegger. Particularmente relevantes son los planteos realizados durante los años Veinte y Treinta. Allí Heidegger tematiza especialmente la conexión entre imagen y producción y reflexiona sobre los alcances ontológicos de dicha conexión.

Entre los intérpretes de Heidegger predomina una lectura que destaca la postura negativa de Heidegger hacia la producción, la exhibición (Darstellung) y la imagen. En dicha lectura ocupan el centro de la atención la crítica heideggeriana al modelo de la producción, efectuada a lo largo de los años Veinte, así como su enfática crítica a la exhibición en la conferencia sobre el origen de la obra de arte, y muy especialmente la noción de imagen presentada en la conferencia "La época de la imagen del mundo". ${ }^{1}$

Sin embargo, esto es solo un aspecto de la elaboración heideggeriana sobre el fenómeno de la imagen. Se trata, por así decir, de la pars destruens de un proyecto mayor. Los intérpretes suelen pasar por alto precisamente la pars construens, esto es, el momento propositivo. En el presente trabajo quisiera mostrar, en primer lugar, que la crítica heideggeriana a la producción y a la imagen es el reverso de una tarea positiva de apropiación, esto es, la elaboración de una ontología de la imagen o figura de cuño propio. En segundo lugar, mostraré cómo Heidegger llevó a cabo dicha ontología de la imagen mediante una creativa recepción de Kant, focalizada en la cuestión de la exhibitio originaria.

\section{Constitución de sentido y producción de imágenes}

En su escrito de 1922 enviado a Natorp, Heidegger critica la noción griega de theoria como un concepto no acreditable en la experiencia humana, construido mediante la radicalización de la experiencia de la producción. ${ }^{2}$ En la Lección de 1927 "Los Problemas fundamentales de la fenomenología”, elabora con mayor detalle su crítica al modelo de la producción. Lo propio de éste, para

1 Entre tales lecturas podemos mencionar, a modo de ejemplo, los siguientes casos: Mitchell caracteriza a Heidegger como un "iconoclasta" (Mitchell, WTJ: El giro pictorial. Una respuesta. Correspondencia entre Gottfried Boehm y WJ Mitchell, en García Varas, A. (ed.) Filosofía de la imagen. Salamanca, Edición Universidad de Salamanca, 2012, 76.) Por otra parte, Taminiaux acentúa el rechazo de Heidegger a la noción de exhibición (Darstellung): Taminiaux, J. (2005). Art et événement. Spéculation et jugement des Grecs à Heidegger. París: Belin, p. 121-126; Taminiaux, J. (2007) “Au croisement de quatre approaches phénoménologiques de l'oeuvre d'art”, en Alter 15 (2007), 11-26, esp. 16 sg.

$2 \mathrm{GA} 62,385 \mathrm{sg}$. 
Heidegger, es la orientación hacia el producto final como algo separado y completo, que descansa en sí mismo. Sobre ello se apoya la noción de acabamiento, en el sentido del estar listo (Fertigsein). "La comprensión de ser del ente correspondiente al comportamiento de producción toma de antemano a tal ente como algo independiente y por liberar para sí mismo. El ser que es comprendido en el comportamiento de producción, es precisamente el ser en sí de lo que está listo". (GA 24, 160) El estar-listo o producido tiene el carácter de la presencia constante (ständige Anwesenheit). $4^{3}$

La noción de imagen aquí implicada es, ante todo, la de la imagen previa o modelo (Vorbild) que guía la producción. Se trata del eidos o presencia previa de aquello por producir. En este sentido, Heidegger afirma:

Todo formar y configurar se ejecuta siguiendo el hilo conductor y la medida de una imagen en el sentido de una imagen previa o modelo. (...) El eidos como el aspecto, anticipado en la imaginación, de aquello por acuñar, da la cosa respecto a lo que ella ya era y es antes de toda realización efectiva (GA 24, $150 \mathrm{sg}$.).

El planteo de Heidegger apunta a mostrar que las características de acabamiento e independencia del producto terminado derivan en última instancia de la imagen previa o modelo. En este sentido, podemos decir que el núcleo del modelo ontológico de la producción que Heidegger critica consiste en la estructura de la imagen como modelo en tanto que presencia constante, la cual predetermina al ente como algo que yace en sí mismo, liberado de la relación con su génesis.

Ahora bien, junto con esta crítica a la imagen o figura, Heidegger lleva a cabo una elaboración positiva de la temática. El programa filosófico de Ser y Tiempo, tanto en su pregunta conductora como en su desarrollo, vuelve sobre la estructura de la producción y la imagen.

Con respecto a la pregunta conductora, esto es, la pregunta por el sentido de ser o Seinsfrage, cabe recordar lo siguiente: Heidegger desarrolla la noción de "sentido" con vistas al problema de la manifestación de todo ente a partir de su ser. Desde tal enfoque, "sentido" quiere decir la forma estructurante y el ámbito así estructurado de las determinaciones de ser, en correlación con procesos fun-

3Cf. GA 24, $153 \mathrm{sg}$. 
damentales de comprensión. Preguntar por el sentido del ser significa entonces investigar el carácter de sentido de las determinaciones ontológicas, esto es, preguntar "por el ser mismo en tanto que inmerso en la comprensibilidad del Dasein" (ST, 175; SZ, 152). El hecho de que Heidegger haya encaminado tal investigación en dirección al tiempo nos indica que su pregunta está dirigida hacia la dinámica en la cual se constituye la dimensión de las determinaciones ontológicas como ámbito de sentido. La pregunta pone en marcha una investigación sobre ser y tiempo, en el sentido de un estudio sobre la dinámica de constitución de sentido.

Ahora bien, para explicitar el proceso de generación del ámbito de comprensibilidad del ente, esto es, la constitución de sentido, Heidegger recurre a la doctrina kantiana del esquematismo trascendental. El resultado de tal apropiación es la idea de que la movilidad originante del sentido de ser es formación configuradora de esquemas (Schemabildung). Y que esto a su vez es el tiempo mismo en su autoformación. Para llegar a esta idea, Heidegger recoge la concepción kantiana, según la cual la imaginación trascendental efectúa la síntesis trascendental entre multiplicidad sensible y unidad aperceptiva y además produce esquemas trascendentales o determinaciones de tiempo que median entre las categorías y la multiplicidad intuible. Para Heidegger se trata de un mismo y único proceso: la síntesis trascendental es esquematización y con ello formación de la intuición pura tiempo.

Diversos intérpretes han señalado con detalle las múltiples operaciones de transformación- apropiación que Heidegger desarrolla aquí. A los fines de la presente exposición consideraremos solamente en líneas generales su interpretación de la relación entre intuición pura, esquematismo trascendental y categorías.

La noción de intuición pura es relevante para Heidegger en cuanto remite al problema del origen de la experiencia finita. Heidegger encuentra en Kant una clave para desarrollar este problema en la medida en que Kant vincula la intuición pura tiempo con la producción trascendental de esquemas. Veamos esto con mayor detenimiento.

Para Heidegger, el conocimiento es finito cuando es afectado por el ente que se muestra. Y este mostrarse es tal, que el ente ofrece inmediatamente un aspecto. Éste no ocupa el lugar del ente. Se trata más bien de que el ente se muestra siempre en un aspecto, mejor dicho, en "su" aspecto. En este sentido, intuir significa tomar inmediatamente al ente que se ofrece en su aspecto. Se trata de lo que Kant llama intuitus derivativus en oposición al intuitus originarius divino. 
Ahora bien, la intuición empírica es posible como tal solamente gracias a una intuición a priori, trascendental. Ésta no recibe al ente que se muestra, sino que hace posible tal manifestación. Asimismo, ella no crea al ente, pues se trata de una intuición finita. Ella posibilita la experiencia del ente, en tanto produce el aspecto puro.

El aspecto puro no es ni el aspecto inmediato, empírico, de un ente, ni el aspecto en el sentido derivado de la copia (Abbild) del ente. Se trata del aspecto de algo en general, es decir, de la prefiguración (Vorzeichnung) del darse en aspectos del ente. Para caracterizar al aspecto puro in statu nascendi, Heidegger utiliza el término "Bild" (figura, imagen). El núcleo de tal planteo consiste en que la figura o imagen pura surge en relación a un configurar o formar (Bilden). Éste consiste, por una parte, en producir la figura o imagen, y por otra parte, en dejar que ésta se ofrezca, pues lo propio de la imagen es ofrecerse a la mirada. Se trata de un vínculo espontáneo y receptivo a la vez.

Contra la distinción kantiana entre esquema trascendental e imagen, Heidegger interpreta el esquema trascendental como imagen pura y el esquematismo trascendental como producción de imágenes puras. Puesto que para Heidegger la aparición es un momento estructural de todo ente, la imagen pura, en tanto prefiguración de la manifestación en aspecto, vale para él como una determinación ontológica primaria. Sobre esto se basa también su crítica al primado de los conceptos puros. En el planteo heideggeriano, las categorías son un derivado de los esquemas trascendentales, obtenido reductivamente al ignorar las condiciones de la manifestación finita.

Para Heidegger, la producción de las imágenes o aspectos puros no es otra cosa que el esquematismo trascendental. Contra la distinción kantiana entre esquema e imagen, Heidegger reconoce en el esquema trascendental el carácter de figura o imagen de las determinaciones ontológicas, gracias al cual éstas pueden determinar la manifestación finita del ente. Aún más, la esquematización no es entendida como un proceso exterior a tales determinaciones, sino más bien como el proceso en que éstas surgen, pues para Heidegger las determinaciones ontológicas conciernen de suyo a la manifestación del ente en aspecto. Pensado a fondo, esto significa "el rechazo fundamental del carácter de las categorías como conceptos puros del entendimiento (...) significa la negación de la idea de conceptos puros del entendimiento" (GA 25, 403). Dicho en otras palabras: la noción misma de concepto puro o función pura del pensar sería una derivación de la estructura fundamental de los esquemas o imágenes puras. 
Al desarrollar su teoría del esquematismo, Heidegger toma de la Antropología en sentido pragmático la caracterización de la imaginación productiva como "poética" (dichtend) y como "exhibitio originaria", en contraposición a la imaginación meramente reproductiva (exhibitio derivativa). En el texto kantiano el carácter originario está pensado en relación con la originalidad del genio artístico. Heidegger, por su parte, entiende el carácter "originario" con vistas a la manifestación de los entes. Si la imaginación consiste para Kant en hacer presente algo que no está (como en el recuerdo o la fantasía), para Heidegger se trata ante todo de que lo que se manifiesta ya está determinado formalmente por una producción de imágenes de carácter fundamental. El carácter poético, es decir, productivo, de la imaginación, resulta interpretado en esta perspectiva ontológica como la productividad de las imágenes puras por parte del tiempo:

Las intuiciones puras son, de acuerdo a su esencia, una presentación (Darstellung) "originaria" de lo intuíble, es decir, una presentación tal, que lo hace surgir: exhibitio originaria. Ahora bien, en este presentar reside la esencia de la imaginación pura. La intuición pura sólo puede ser "originaria", porque es en su esencia imaginación pura, que da desde sí aspectos (imágenes), en tanto los forma. (GA 3, $141 \mathrm{sg}$.)

Sostener que la intuición pura es, en el fondo, producción de imágenes puras, significa reconducir el intuitus derivativus hacia la exhibitio originaria. A la base de tal operación se encuentra el siguiente planteo: la producción de figuras o imágenes puras, entendida como proyección configuradora de un entramado u horizonte de sentido, es la dinámica originaria de la experiencia humana y de los fenómenos.

Ésta resulta caracterizada también como "temporalidad originaria" (GA 24, 379) y "autoproyecto" (GA 24, 436 sg.). En la correlación entre éxtasis esquematizadores y horizonte esquematizado encuentra Heidegger la dinámica que da origen al carácter de sentido de las determinaciones que prefiguran la manifestación de lo que hay, es decir, la dinámica de estructuración formal del ámbito de comprensibilidad del ente. Pasado, presente y futuro son modos articulables entre sí que proporcionan el formato, en la dinámica de esquematización, para toda determinación ontológica. 
A partir de lo dicho resulta claro que, a diferencia de lo que ocurre en el modelo tradicional de la poiêsis, en el esquematismo heideggeriano el producto (imagen pura) no es separable del proceso de su propia producción. La imagen pura es solamente en dicha producción, la cual consiste en formar y dejar lucir a la vez. Se trata pues de un tipo de producción sui generis, en la cual el producto no yace separado de la relación productiva. Heidegger acentúa este rasgo al interpretar la producción de imágenes puras como la relación circular entre proyección y horizonte de proyección.

Otro punto de diferencia con el modelo tradicional concierne a la forma o plan que guía la producción. Para dicho modelo, se trata de una forma prototípica, respecto a la cual cada producto concreto es en cierto sentido una réplica. En la concepción sobre la producción de la imagen pura, en cambio, no tiene sentido intentar diferenciar entre original y reproducción. Esto conduce a la paradojal estructura de un producto que guía su propia producción, o bien de un "ver" proyectante que, al ver anticipatoriamente la forma o modelo de producción, la deja ser - y en ello consiste precisamente la producción -. En este sentido afirma Heidegger:

Pero qué tipo de mirar es éste? No se trata de ningún mirar a algo, como cuando miramos con curiosidad algo que está ahí delante.[...] Se trata más bien de un captar con la mirada, es decir: mediante el mirar y en el mirar formar lo captado (el aspecto), formarlo de antemano, prefigurarlo (GA 34, 71).

El modelo de producción puesto en juego aquí es pues un ver y producir sui generis: un producir imágenes en el cual la imagen que guía la producción es el producto mismo; una producción que es a la vez un ver, el ver anticipatoriamente la imagen conductora o modelo, produciéndola, y siendo guiado por ella.

De acuerdo a esto, la imagen originaria o esquema trascendental no tiene el carácter del estar-presente de modo fijo, acabadamente. El enfoque heideggeriano considera a la imagen modelo in statu nascendi y en una tensión constitutiva, a saber: en la circularidad entre el proyectar o producir esquematizador y el horizonte esquematizado. 


\section{El arte como producción de imágenes originaria}

En los últimos años de la década de 1920, Heidegger experimenta los límites internos de su programa del esquematismo. Un documento de esta crisis es la Lección de 1929/30 Los conceptos fundamentales de la Metafísica. Allí, después de su intento por explicitar la estructura de la proyección como formación de mundo, Heidegger afirma:

También la filosofía trascendental debe caer. (...) También la ontología y su idea deben caer, precisamente porque la radicalización de esa idea fue un estadio necesario del desarrollo de la problemática fundamental de la Metafísica (GA 29/30, 522).

Sobre los motivos de esta crisis se puede afirmar lo siguiente: Heidegger advierte que la explicación del mostrarse del ente a partir de su horizonte de sentido se concentra en el momento de la accesibilidad y no desarrolla apropiadamente la tensión con la inaccesibilidad y la retracción de sentido. Asimismo, reconoce en el acento puesto en el poder proyectante del Dasein un rasgo de la filosofía trascendental del sujeto, de la cual él sin embargo intentaba tomar distancia.

Uno de los modos más recurrentes de expresar esta autocrítica fue la caracterización de la orientación platónica hacia la idea como una nivelación, hacia el plano de lo visible y manifiesto, de la tensión aléthica entre ocultamiento y manifestación. Esta objeción a Platón puede ser entendida como una crítica al propio programa del esquematismo, dado que Heidegger había hecho converger expresamente el esquema trascendental kantiano y la idea platónica en la estructura de la imagen o aspecto puro, la cual configura a priori y "hace visible" a su horizonte.

Ahora bien, los intentos de Heidegger por salir de la crisis están marcados por una reflexión constante sobre la producción de figuras o imágenes. Si bien toma distancia respecto a la orientación hacia lo "visible", Heidegger no renuncia a la búsqueda de una producción de sentido paradigmática, entendida como formación de figuras. En el marco de esta búsqueda tiene lugar su encaminamiento hacia el arte.

Tanto la teoría heideggeriana del esquematismo como su posterior concepción sobre el arte pueden entenderse como dos modulaciones de un enfoque 
dirigido hacia la producción como exhibición originaria de imágenes o figuras. Por una parte, Heidegger caracteriza la producción de esquemas trascendentales como exhibitio originaria en sentido ontológico, y por otra parte, tras la crisis de su programa trascendental, lleva a cabo una investigación acerca del arte como producción (Dichtung, Hervorbringung) ontológicamente originaria.

Es menester aquí esclarecer dos cuestiones fundamentales: Primero: ¿qué rol tiene la función exhibitoria de las imágenes o figuras en la concepción heideggeriana sobre el arte? Segundo: ¿en qué sentido la originariedad del arte puede entenderse con vistas a la producción de imágenes o figuras?

Para desarrollar estas cuestiones hay que comenzar por considerar la primera elaboración del tratado sobre el origen de la obra de arte (1931). La tesis central del tratado afirma que el arte consiste en "poner en obra la verdad" y es por ello el origen de la obra de arte. En tal sentido, el arte es caracterizado como producción (Dichtung). Los principales ejemplos ofrecidos son el templo de Apolo, la estatua de Zeus, la tragedia griega y la poesía de Hölderlin (EA, 7,12; EAtr, 14, 21). En este sentido amplio, Dichtung se dice tanto respecto de figuras (estatuas, construcciones) como de palabras. Lo pictórico no ocupa ningún lugar destacado. Los análisis del cuadro de Van Gogh, tan relevantes en la versión publicada, no aparecen aún.

Para entender mejor los alcances de esta orientación inicial hacia las artes plásticas y no hacia la pintura, es relevante considerar la nota al pie inicial de la edición de Reclam del tratado sobre el arte. Allí Heidegger caracteriza al arte como traer-delante-desde (Her-vor- bringen) - una expresión que significa "producción" - y remite al texto Lenguaje y hogar de 1960. En un pasaje central de dicho texto se afirma:

\footnotetext{
"formar" [bilden] proviene del verbo "pilon" en antiguo alto alemán, que significa impeler, empujar, empujar hacia delante. Formar es traer-delante-desde [Her-vorbringen], a saber: delante en lo desoculto y manifiesto, desde lo oculto y lo autoocultante. Lo traído-delante en este sentido, es decir, lo formado, es la configuración [Gebild]. En tanto aparece y con ello luce, ofrece éste un aspecto y es, como configuración, a la vez la figura [Bild] originaria. Toda copia e imitación es por el contrario figura en un sentido derivado. Esto se encuentra ya en el sustantivo latino imago, del cual procede imi-
} 
tari -imitar, formar posteriormente-. La palabra ícono, que proviene del griego, tiene en cambio un sentido más profundo. Procede del verbo eiko, que significa: retroceder ante algo y así dejarlo advenir y con ello dejarlo aparecer. La figura pertenece originariamente como configuración al traer-delante, y no al revés. (GA 13, 171 sg.)

Mediante el recurso a la etimología griega y germana, Heidegger intenta aquí exponer un modelo de producción ontológica de figuras compatible con su concepción sobre la aletheia como tensión entre manifestación y autoocultamiento. Su exposición destaca lo siguiente: Primero, la figura originaria es lo traído-delante, la configuración (Gebild), es decir, pertenece constitutivamente al proceso del formar configurador (Bilden). Segundo, tal formar consiste en la dinámica plástica del forjar o modelar (plassein), entendida como la puesta en tensión de dos direcciones: desde el origen que se sustrae y hacia la instancia de lucimiento o manifestación.

Asimismo, esta concepción plástica de la producción y la figura originaria es puesta en contraste con la concepción de Bild como imago. Si bien en el pasaje citado el término latino aparece únicamente en relación con la estructura de la imitación, se puede conectar la crítica a imago con la denuncia heideggeriana, presentada a inicios de los años Treinta, a la operación platónica consistente en privilegiar la visibilidad de la idea por encima de la aletheia. En este sentido, el contraste planteado entre configuración e imago remitiría, en última instancia, al contraste entre una concepción plástica - cercana al modelo de la aletheia y una concepción óptica orientada hacia las condiciones de "visibilidad" de lo manifiesto, dentro de la cual cabría situar incluso al esquematismo heideggeriano. Esta repulsa de la imagen a favor de la configuración permite entender también la ausencia de referencias a la pintura y la concentración en la construcción y la escultura en la primera versión del tratado sobre el arte.

A partir de lo expuesto podemos distinguir entre los dos sentidos de la expresión Bild que hasta ahora habíamos mantenido unidos: por una parte, Bild en cuanto imagen; por otra parte, en cuanto figura. El paso del esquematismo de Heidegger a sus estudios sobre el arte puede caracterizarse como el paso de una ontología de la imagen a una ontología de la figura. ${ }^{4}$

4Esto no significa negar de ninguna manera una posterior reapropiación de la visualidad en los planteos de Heidegger sobre el arte. Conforme a lo dicho, la introducción de la referencia a la pintura en la segunda versión del tratado del arte (1935) puede entenderse como la gestación de una concepción sobre el lucir y el aspecto en el marco de la noción de figura originaria obtenida inicialmente mediante la orientación hacia la producción plástica. 
Estamos ya en condiciones de desarrollar las cuestiones planteadas anteriormente. Con relación a la primera, cabe señalar lo siguiente: De la mano de los ejemplos de la producción plástica, Heidegger elabora su concepción sobre el carácter poético (dichtend), es decir productivo -no reproductivo- del arte. La figura (Bild) es entendida en el sentido eminente del templo que se yergue o de la estatua en cuanto "figura estante" (Standbild):

El templo que se eleva sobre la montaña o en un valle rocoso; la estatua que está de pie en el área sagrada: estas obras no están simplemente también presentes entre todo lo demás (...) ellas son más reales que cualquier cosa, porque cada cosa puede anunciarse como siendo recién en lo abierto conquistado por la obra”. (EA, 15) "Elevándose en un mundo y retrayéndose en la tierra, el templo inaugura el Ahí (...). (EA, 12)

De acuerdo a lo expuesto, la función exhibitoria no es comprendida como reproducción a partir de un modelo. Lo relevante no es si la estatua "representa" tal o cual cosa, sino que ella, en cuanto "está de pie", remite al suelo que la soporta y a lo alto, hacia donde se yergue, y a la vez hace patente su irrupción en el espacio, con lo cual éste queda reconfigurado.

Podría objetarse la presente interpretación señalando que Heidegger no llama a esto exhibición y que además rechaza expresamente la noción de Darstellung. Frente a ello hay que mencionar que la crítica heideggeriana a la concepción del arte como Darstellung está elaborada en correlación con su caracterización del arte como Dichtung y descansa sobre la oposición entre una manifestación "dichtend" (poética, productiva) y una manifestación reproductiva. La distinción entre exhibitio originaria y exhibitio derivativa opera pues implícitamente en el tratado sobre el arte.

Las características del aparecer concreto de la obra de arte plástica antes mencionadas son interpretadas ontológicamente por Heidegger en el siguiente sentido: la obra "pone" al mundo mediante el "poner en lo abierto" o instalación (Aufstellung) y "pone" a la tierra mediante el "poner aquí desde" o elaboración (Herstellung). Este doble "poner", constitutivo de la obra, es el despliegue de un "combate" (Streit) en la que las instancias de lo abierto (mundo) y de la retracción de sentido (tierra) alcanzan una interrelación constitutiva. 
Al interpretar el "estar de pie" de la obra como un "poner", Heidegger parecería quedar expuesto a la objeción de que simplemente ha traspuesto la causalidad eficiente hacia la obra misma, es decir, que ha hecho de la obra una suerte de productor. Sin embargo, su planteo no pretende afirmar que la obra se ponga a sí misma, sino más bien que la obra es la puesta en tensión de instancias heterogéneas (manifestación y ocultamiento, mundo y tierra). Esa tensión acontece en y como obra de arte. La característica propia de tal modo de acontecer es que resulta patente.

De acuerdo a lo anterior, la obra de arte por su carácter de figura irrumpe ${ }^{5}$, es decir, aparece haciendo patente su venir a presencia y junto con ello la tensión entre manifestación y ocultamiento que lo condiciona. Su función exhibitoria consiste entonces en mostrarse in statu nascendi. Su carácter de figura (Bild) no radica en un lucir completamente aprehensible, sino más bien en un ofrecerse a la captación, manifiestando su propia opacidad y resistencia. Si durante su esquematismo Heidegger planteaba la noción de la imagen-esquema trascendental (transzendentales Schema-Bild) que hace visible al horizonte, durante su aproximación al arte propone, en cambio, la noción de la figura estante (Standbild). En relación a ello, Heidegger habla de un "parar" (zum Stehen bringen) la verdad en la obra de arte. (GA 5, 62). "Parar" significa a la vez fijar o dar estancia y poner de pie: con ello se indica que la tensión aléthica adquiere cierta estabilidad y fijeza, pero que a la vez irrumpe, se patentiza en su propio aparecer desde una tensión.

Los planteos heideggerianos sobre el arte traen consigo una reelaboración de la noción de ser como presencia constante (ständige Anwesenheit). La exhibición artística es un traer a presencia tal, que en él se evidencia el aparecer del ente desde su tensión constitutiva, esto es, su "estar de pie" (stehen). A partir de esta noción del "estar de pie", Heidegger elabora en los años Treinta un conjunto de términos relacionados, una semántica de la estancialidad (Ständigkeit). ${ }^{6}$

Consideremos ahora la segunda cuestión, esto es, en qué sentido la originariedad del arte, tal como la plantea Heidegger, se entiende con vistas a la producción de imágenes.

En la primera versión del tratado sobre el arte, se explicita el carácter originario del arte del siguiente modo:

5 Para destacar este carácter de irrupción, es decir, la característica auto-patentizante del venir a presencia, Heidegger refiere a la figura como "Riss", palabra alemana que puede significar rasgo, fisura, trazo, surco o hendidura.

6En la lección de 1935 Introducción a la metafisica de 1935, revisada y publicada en 1953, Heidegger profundiza la conceptualidad en torno al "estar de pie" (Stehen). Allí utiliza como términos técnicos expresiones tales como Dastehen (estar de pie ahí), Ständigkeit (estancialidad), Zum Stand bringen (poner de pie, realizar), etc. Cf. GA 40, 17, 63-68, 139-142, 194-197. 
El arte deja a su modo surgir la verdad, es un dejar surgir, un origen. El arte es en su esencia más íntima origen y sólo eso (...) Porque es esencialmente el dejar surgir la verdad, el arte es también el fundamento de necesidad de la obra. (EA 20)

El sentido de este "originar" como relación entre obra de arte y verdad aparece en la fórmula heideggeriana según la cual "el arte pone en obra la verdad". Este "poner en obra" la verdad, el rendimiento originario del arte, es la producción (Dichtung, Hervorbringung) en tanto que esencia del arte. No se trata de la producción de obras o figuras en el sentido habitual de la confección de objetos por parte del productor, sino del evento manifestativo que ocurre en la experiencia de la obra de arte.

En otras palabras, no se trata de que obras de arte sean confeccionadas, sino de que con ellas tiene lugar un peculiar proceso manifestativo, al que Heidegger llama producción (Dichtung, Hervorbringung). El arte es producción de figuras ontológicamente originaria en el sentido de que es una tensión entre instancias de manifestación y retracción de sentido en la que surge un ente (obra de arte, figura) que se exhibe originariamente, es decir, que patentiza su propio surgimiento y las condiciones de éste.

\section{Conclusión}

Hemos visto que Heidegger elabora positivamente una ontología de la imagen o figura (Bild) concentrándose precisamente en los núcleos de su crítica a la ontología tradicional de la imagen, esto es, la conexión entre imagen y producción y la concepción del ser como presencia constante. Este procedimiento de crítica y reelaboración corresponde a lo que Heidegger llama "destrucción".

Los principales momentos de esta destrucción de la imagen en el período estudiado corresponden a dos sentidos del término Bild: como imagen y como figura. El paso del esquematismo de Heidegger hacia su aproximación al arte es el paso desde una concepción óptica hacia una concepción plástica sobre Bild y Bilden, elaboradas con vistas al tópico kantiano de la exhibitio originaria.

Ahora bien, a partir de estos resultados interpretativos surgen nuevas cuestiones, en particular respecto a la aproximación heideggeriana al arte. 
La primera cuestión puede plantearse así: para Heidegger, la obra de arte hace patente su propio aparecer y la tensión aléthica que lo condiciona. En la obra viene a presencia una presencia inédita, de primer orden, no una representación. Esto podría entenderse como la generación conjunta de sentido y presencia. Pero entonces, ¿qué características posee el "sentido”, más específicamente, el carácter significativo de la obra de arte? Pareciera que no se trata de significaciones objetivas ni cósicas, pero tampoco de significaciones práctico-operativas, como las que prefiguran la experiencia instrumental cotidiana. Pero entonces, ¿cuál es el carácter propio de las significaciones operantes en la experiencia de obras de arte?

Se impone además una segunda cuestión. El planteo heideggeriano respecto al rendimiento del arte como un poner en obra la verdad aparece inicialmente de la mano con el énfasis en la plasticidad y tiene como trasfondo la autocrítica hacia la concepción óptica del esquematismo, orientada hacia la visibilidad de lo manifiesto. Poco después, sin embargo, en la segunda versión del tratado, la pintura ocupa un lugar central. Ahora bien, ¿cómo elabora Heidegger la visualidad de las obras pictóricas en compatibilidad con el énfasis en las instancias de ocultamiento y retracción de sentido, propio de su ontología del arte? ¿Cómo entender la conexión entre carácter de imagen y carácter significativo, toda vez que Heidegger ha renunciado a una doctrina del esquematismo?

Recebido em: 26.11.2013 | Aprovado em: 01.02.2014

Heidegger, M. Die Grundprobleme der Phänomenologie. Fráncfort: Klostermann, 1975. (GA24)

.Einführung in die Metaphysik. Fráncfort: Klostermann, 1976 (GA 40).

.Die Grundbegriffe der Metaphysisk. Welt Endlichkeit - Einsamkeit. Fráncfort: Klostermann, 1983. (GA 29/30)
.Aus der Erfahung des Denkens. Fráncfort: Klostermann, 1983. (GA 13)

.Vom Wesen der Wahrheit. Zu Platons Hohlengleichnis und Theätet. Fráncfort: Klostermann, 1988. (GA 34)

Phänomenologische Interpretationen
ausgewählter Abhandlungen des Aristoteles zur Ontologie
und Logik. Fráncfort: Klostermann, 2002 (GA62)


.Vom Ursprung des Kunstwerks: Erste

Ausarbeitung", Heidegger-Studies 5 (1989) 5-22. (EA) . Kant und das Problem der Metaphysik.

Fráncfort: Klostermann, 1991. (GA3)

Mitchell, WTJ: "El giro pictorial. Una respuesta. Correspondencia entre Gottfried Boehm y WJ Mitchell', en García Varas, A. (ed.) Filosofia de la imagen. Salamanca, Edición Universidad de Salamanca, 2012, 71-87.

Taminiaux, J. (2005). Art et événement. Spéculation et jugement des Grecs à Heidegger. París: Belin, 2005.

Taminiaux, J. "Au croisement de quatre approaches phénoménologiques de l'oeuvre d'art'. En Alter (15), 11-26, 2007. 